\title{
International Geomagnetic Reference Field: the Third Generation
}

\author{
Norman W. PEDDIE* \\ U.S. Geological Survey, Mail Stop 964. \\ Federal Center Box 25046, Denver, Colorado 80225, U.S.A.
}

(Received April 6, 1982)

\begin{abstract}
In August 1981 the International Association of Geomagnetism and Aeronomy revised the International Geomagnetic Reference Field (IGRF). It is the second revision since the inception of the IGRF in 1968. The revision extends the earlier series of IGRF models from 1980 to 1985, introduces a new series of definitive models for 1965-1975, and defines a provisional reference field for 1975-1980. The revision consists of : (1) a model of the main geomagnetic field at 1980.0, not continuous with the earlier series of IGRF models, together with a forecast model of the secular variation of the main field during 1980-1985; (2) definitive models of the main field at 1965.0,1970.0, and 1975.0, with linear interpolation of the model coefficients specified for intervening dates; and (3) a provisional reference field for 1975-1980, defined as the linear interpolation of the 1975 and 1980 main-field models. The new models are series of solid spherical harmonics up to and including the tenth degree and order for the main-field models, and up to and including the eighth degree and order for the secular variation model. The models were derived from three sets of proposed models by taking weighted means. The weights were chosen according to the apparent accuracy of the proposed models. A brief history of the IGRF, a review of basic formulas, and a set of world contour maps of the geomagnetic elements based on the IGRF 1980 model are included.
\end{abstract}

\section{Introduction}

In August of 1981, a new revision of the International Geomagnetic Reference Field (IGRF) was approved by the International Association of Geomagnetism and Aeronomy (IAGA). The new revision, the third generation of the IGRF, extends the earlier series of models five more years, up to 1985. In addition, it introduces a new series of definitive models which spans 1965-1975 and it specifies a provisional reference field for 1975-1980.

The IGRF is a quantitative description of the Earth's main magnetic field. By "main field" we mean the field of internal origin, excluding both the part caused by magnetic material in the crust and the part caused by internal electric currents induced by external magnetic fields. It is believed that the main field is caused by electric currents in the Earth's liquid core that are sustained by internal sources of energy. With the new revision, the IGRF now describes the main field from 1955 to 1985.

The IGRF was conceived to meet

"the need for a reference field to form an agreed basis for main-field calculations and to unify results in studies on, for example, removal of trend to yield surface anomalies,

*Chairman, Working Group I-1, International Association of Geomagnetism and Aeronomy. 
field residuals potentially applicable to the calculation of ionospheric and magnetospheric currents, the shape of a field line, locations of conjugate points, and field values used in the B-L space of trapped particles" (ZMUDA, 1971, p. 148).

\section{The First and Second Generations of the IGRF}

The original or first generation of the IGRF was adopted in 1968 (IAGA CoMmIssion 2 WORKING GROUP 4, 1969). It consists of a model of the main field at 1965.0 and a model of the secular variation (i.e., the change with time) of the main field. Taken together, they are called IGRF 1965. Each model is defined by a series of (80) solid, internal spherical harmonics up to and including the eighth degree and order. The model of secular variation was provided so that the main-field model could be extended or extrapolated in time, both backward and forward. The limit on backward extrapolation is 1955.0, and the limit on forward extrapolation is 1975.0. ZMUDA (1971, pp. 147-205) gives a full account of the development of the original IGRF, and includes evaluations of the models that were proposed, contour maps of the magnetic elements, and a comprehensive list of references.

The secular variation of the main field is complex and, as yet, not predictable. The model of secular variation included with IGRF 1965, and indeed all the secular variation models associated with the IGRF, are simple linear models. They specify constant rates of change of the main-field coefficients. This kind of model can closely approximate the secular variation, but usually only for a span of a few years. After an extrapolation of ten years, up to 1975, IGRF 1965 is very inaccurate for some regions (e.g., PETKovic and Whit wORTH, 1975; Dawson and NewITT, 1978; MEAD, 1979). The first revision of the IGRF corrected the secular variation model, but did not correct the error that had accumulated in the main-field coefficients after being extrapolated to 1975 .

The first revision or second generation of the IGRF was adopted in 1975 (IAGA Division I STUdy Group, 1975, 1976, 1977). It consists of a model of the main field at 1975.0 and a forecast model of the secular variation during 1975-1980. Taken together, they are called IGRF 1975. The main-field model is simply the main-field model of IGRF 1965 extrapolated to 1975.0. Hence, IGRF 1975 is continuous with IGRF 1965. The secular variation model was new, and like the earlier one, is defined by a series of $(80)$ solid, internal spherical harmonics up to and including the eighth degree and order.

By the early 1970's, it had become clear that merely revising the secular variation model periodically would not keep the IGRF "on track," or faithful to the real main field. For the second revision of the IGRF it was decided that continuity with the preceding models would not be required. However, it was decided also that the second revision would introduce a new series of "definitive" models that would be continuous and would faithfully represent the real main field.

\section{The Third Generation of the IGRF}

The form of the second revision or third generation of the IGRF was specified by IAGA Working Group I-1 in December 1979 at the General Assembly in Canberra (FUKUSHIMA, 1980). It would consist of spherical harmonic models of the main field at 1965.0, 1970.0, 1975.0, and 1980.0 and of the secular variation during 1980-1985. Maximum degree and order would lie in the range eight to ten. The models for 1965.0, 
1970.0, and 1975.0 would be considered definitive because they would be derived from sets of data that are unlikely ever to be significantly increased or improved. The model for 1980.0 would not be continuous with IGRF 1975 extrapolated to 1980.0.

Three sets of models were proposed, one each from modeling groups at the U.S. National Aeronautics and Space Administration (NASA) (LANGEL et al., 1982a), the U.K. Institute of Geological Sciences (IGS) (BARRACLOUGH et al., 1982), and the U.S. Geological Survey (USGS) (PEDDIE and FABIANO, 1982a). The three proposals reflect three different approaches to the problem of creating the most accurate models of the main field and its secular variation: The models proposed by NASA resulted from an analysis of MAGSAT (LANGEL et al., 1982b), observatory, and other data, in which the spatial and temporal terms were combined, and in which parameters representing magnetic anomalies at the observatory sites were included. The models proposed by IGS were derived from several models that had been developed prior to the advent of MAGSAT, and a new analysis of recent secular variation using chiefly observatory and satellite data. The models proposed by USGS were derived by extrapolating a main-field model based on MAGSAT data to the required epochs by means of a new series of secular variation models based on observatory data.

Seven reports of assessments of the proposed models were presented at the Fourth Scientific Assembly of IAGA at Edinburgh. Six of them (BARRAClOUGH, 1982; DA wSON and NewitT, 1982; LANGEL and Estes, 1982; MCGREGOR et al., 1982; OstrowSKI, 1982; PedDie and Fabiano, 1982b) are included in this issue, the other one was given by F. S. Barker. On the basis of these assessments, the Working Group recommended a revision of the IGRF consisting of models that are defined as weighted means of the coefficients of the proposed models. The relative weights (Table 1) were chosen according to the apparent accuracy of the proposed models. The recommendation, contained in Resolution 13, was adopted by IAGA on August 15, 1981 (IAGA Division I Working GrouP 1, 1981).

The adopted recommendations established the following:

(1) For 1980.0 to 1985.0 , an international geomagnetic reference field ( IGRF 1980) consisting of a model of the main field at 1980.0 and a forecast model of the secular variation during 1980-1985 to be used for extrapolating the main-field model up to 1985.0.

(2) For 1965.0 to 1975.0 , a definitive international geomagnetic reference field consisting of models of the main field at 1965.0, 1970.0, and 1975.0 (DGRF 1965, DGRF 1970 , and $D G R F 1975$, respectively), with linear interpolation of the model coefficients specified for intervening dates.

(3) For 1975.0 to 1980.0 , a provisional international geomagnetic reference field ( PGRF 1975), defined as the linear interpolation of the coefficients of DGRF 1975 and the main-field coefficients of IGRF 1980.

(4) An intention to follow the pattern of the preceding recommendations in future revisions of the IGRF.

Table 1. Relative weights used to derive the new IGRF models.

\begin{tabular}{lccccc}
\hline & 1965 & 1970 & 1975 & 1980 & $1980-85$ \\
\hline NASA & 20 & 25 & 30 & 50 & 0 \\
IGS & 60 & 50 & 40 & 0 & 2 \\
USGS & 20 & 25 & 30 & 50 & 1 \\
\hline
\end{tabular}


The spherical harmonic coefficients that define the third generation of the IGRF are reproduced here for convenience (Table 2). As is true for the earlier generations of the IGRF, the coefficients are Schmidt quasi-normalized (CHAPMAN and BARTELS, 1940) and refer to a sphere having a radius of $6,371.2 \mathrm{~km}$.

\section{Review of Basic Formulas}

The models that make up the IGRF are series of solid spherical harmonics and their derivatives in geocentric spherical coordinates describing the geomagnetic scalar potential $V$ and the field components through:

$$
\begin{aligned}
V & =a \sum_{n=1}^{N} \sum_{m=0}^{n}\left(\frac{a}{r}\right)^{n+1}\left(g_{n}^{m} \cos m \lambda+h_{n}^{m} \sin m \hat{\lambda}\right) P_{n}^{m}(\cos \theta) \\
X_{\mathrm{c}} & =\frac{1}{r} \frac{\partial V}{\partial \theta} \\
Y_{\mathrm{c}} & =\frac{-1}{r \sin \theta} \frac{\partial V}{\partial \lambda} \\
Z_{\mathrm{c}} & =\frac{\partial V}{\partial r}
\end{aligned}
$$

where $X_{\mathrm{c}}, Y_{\mathrm{c}}$, and $Z_{\mathrm{c}}$ represent, respectively, the northward, eastward, and radially downward components of the field intensity in a local cartesian coordinate system referred to a spherical Earth; a, the radius of the reference sphere, taken to be equal to the approximate mean radius of the Earth $(6,371.2 \mathrm{~km}) ; r$, the radial distance from the center of the Earth; $\theta$, the geocentric colatitude; $\lambda$, the east longitude measured from Greenwich ; $P_{n}^{m}$ $(\cos \theta)$, the associated Legendre function of degree $n$ and order $m$ and of the Schmidt quasinormalized type (CHAPMAN and BARTELS, 1940); $N$, the maximum degree and order; and $g_{n}^{m}$ and $h_{n}^{m}$, the spherical harmonic coefficients in units of nanotesla $(\mathrm{nT})$. One nanotesla equals one gamma.

The figure of the Earth is more nearly an oblate spheroid than a sphere. It is customary to take this into account by converting geographic coordinates, which are assumed to be oblate-spheroidal coordinates, to the required spherical coordinates before evaluating Eqs. (2)-(4), and by converting the resulting field components to field components in a local cartesian coordinate system referred to an oblate-spheroidal Earth. If $A$ and $B$ are, respectively, the equatorial and polar radii of the oblate spheroid, then $\theta$ and $r$ can be derived from:

$$
\cos \theta=\sin \phi /\left(f \cos ^{2} \phi+\sin ^{2} \phi\right)^{1 / 2}
$$

and

$$
\begin{gathered}
r^{2}=h^{2}+2 h\left[A^{2}-\left(A^{2}-B^{2}\right) \sin ^{2} \phi\right]^{1 / 2}+\left[A^{4}-\left(A^{4}-B^{4}\right) \sin ^{2} \phi\right] / \\
{\left[A^{2}-\left(A^{2}-B^{2}\right) \sin ^{2} \phi\right]}
\end{gathered}
$$


Table 2. Spherical harmonic coefficients of the third generation of the IGRF.

\begin{tabular}{|c|c|c|c|c|c|c|c|}
\hline & \multirow{2}{*}{$n$} & \multirow[b]{2}{*}{$m$} & \multicolumn{3}{|c|}{ DGRF } & \multicolumn{2}{|c|}{ IGRF } \\
\hline & & & $\begin{array}{l}1965 \\
(\mathrm{nT})\end{array}$ & $\begin{array}{l}1970 \\
(\mathrm{nT})\end{array}$ & $\begin{array}{l}1975 \\
(\mathrm{nT})\end{array}$ & $\begin{array}{l}1980 \\
(n T)\end{array}$ & $\begin{array}{c}1980-85 \\
(\mathrm{nT} / \mathrm{yr})\end{array}$ \\
\hline g & 1 & 0 & -30334 & -30220 & -30100 & -29988 & 22.4 \\
\hline $\mathrm{g}$ & 1 & 1 & -2119 & -2068 & -2013 & -1957 & 11.3 \\
\hline $\mathrm{h}$ & 1 & 1 & 5776 & 5737 & 5675 & 5606 & -15.9 \\
\hline $\mathrm{g}$ & 2 & 0 & -1662 & -1781 & -1902 & -1997 & -18.3 \\
\hline $\mathrm{g}$ & 2 & 1 & 2997 & 3000 & 3010 & 3028 & 3.2 \\
\hline $\mathrm{h}$ & 2 & 1 & -2016 & -2047 & -2067 & -2129 & -12.7 \\
\hline g & 2 & 2 & 1594 & 1611 & 1632 & 1662 & 7.0 \\
\hline $\mathrm{h}$ & 2 & 2 & 114 & 25 & -68 & -199 & -25.2 \\
\hline $\mathrm{g}$ & 3 & 0 & 1297 & 1287 & 1276 & 1279 & 0.0 \\
\hline g & 3 & 1 & -2038 & -2091 & -2144 & -2181 & -6.5 \\
\hline $\mathrm{h}$ & 3 & 1 & -404 & -366 & -333 & -335 & 0.2 \\
\hline $\mathrm{g}$ & 3 & 2 & 1292 & 1278 & 1260 & 1251 & -0.7 \\
\hline $\mathrm{h}$ & 3 & 2 & 240 & 251 & 262 & 271 & 2.7 \\
\hline $\mathrm{g}$ & 3 & 3 & 856 & 838 & 830 & 833 & 1.0 \\
\hline $\mathrm{h}$ & 3 & 3 & -165 & -196 & -223 & -252 & -7.9 \\
\hline $\mathrm{g}$ & 4 & 0 & 957 & 952 & 946 & 938 & -1.4 \\
\hline $\mathrm{g}$ & 4 & 1 & 804 & 800 & 791 & 783 & -1.4 \\
\hline $\mathrm{h}$ & 4 & 1 & 148 & 167 & 191 & 212 & 4.6 \\
\hline $\mathrm{g}$ & 4 & 2 & 479 & 461 & 438 & 398 & -8.2 \\
\hline $\mathrm{h}$ & 4 & 2 & -269 & -266 & -265 & -257 & 1.6 \\
\hline $\mathrm{g}$ & 4 & 3 & -390 & -395 & -405 & -419 & -1.8 \\
\hline h & 4 & 3 & 13 & 26 & 39 & 53 & 2.9 \\
\hline $\mathrm{g}$ & 4 & 4 & 252 & 234 & 216 & 199 & -5.0 \\
\hline h & 4 & 4 & -269 & -279 & -288 & -298 & 0.4 \\
\hline $\mathrm{g}$ & 5 & 0 & -219 & -216 & -218 & -219 & 1.5 \\
\hline $\mathrm{g}$ & 5 & 1 & 358 & 359 & 356 & 357 & 0.4 \\
\hline $\mathrm{h}$ & 5 & 1 & 19 & 26 & 31 & 46 & 1.8 \\
\hline g & 5 & 2 & 254 & 262 & 264 & 261 & -0.8 \\
\hline h & 5 & 2 & 128 & 139 & 148 & 149 & -0.4 \\
\hline g & 5 & 3 & -31 & -42 & -59 & -74 & -3.3 \\
\hline $\mathrm{h}$ & 5 & 3 & -126 & -139 & -152 & -150 & 0.0 \\
\hline g & 5 & 4 & -157 & -160 & -159 & -162 & 0.2 \\
\hline $\mathrm{h}$ & 5 & 4 & -97 & -91 & -83 & -78 & 1.3 \\
\hline $\mathrm{g}$ & 5 & 5 & -62 & -56 & -49 & -48 & 1.4 \\
\hline$h_{1}$ & 5 & 5 & 81 & 83 & 88 & 92 & 2.1 \\
\hline $\mathrm{g}$ & 6 & 0 & 45 & 43 & 45 & 49 & 0.4 \\
\hline $\mathrm{g}$ & 6 & 1 & 61 & 64 & 66 & 65 & 0.0 \\
\hline $\mathrm{h}$ & 6 & 1 & -11 & -12 & -13 & -15 & -0.5 \\
\hline $\mathrm{g}$ & 6 & 2 & 8 & 15 & 28 & 42 & 3.4 \\
\hline h & 6 & 2 & 100 & 100 & 99 & 93 & -1.4 \\
\hline $\mathrm{g}$ & 6 & 3 & -228 & -212 & -198 & -192 & 0.8 \\
\hline $\mathrm{h}$ & 6 & 3 & 68 & 72 & 75 & 71 & 0.0 \\
\hline g & 6 & 4 & 4 & 2 & 1 & 4 & 0.8 \\
\hline $\mathrm{h}$ & 6 & 4 & -32 & -37 & -41 & -43 & -1.6 \\
\hline $\mathrm{g}$ & 6 & 5 & 1 & 3 & 6 & 14 & 0.3 \\
\hline h & 6 & 5 & -8 & -6 & -4 & -2 & 0.5 \\
\hline
\end{tabular}


Table 2. (continued)

\begin{tabular}{|c|c|c|c|c|c|c|c|}
\hline & \multirow{2}{*}{$n$} & \multirow[b]{2}{*}{$m$} & \multicolumn{3}{|c|}{ DGRF } & \multicolumn{2}{|c|}{ IGRF } \\
\hline & & & $\begin{array}{l}1965 \\
(\mathrm{nT})\end{array}$ & $\begin{array}{l}1970 \\
(\mathrm{nT})\end{array}$ & $\begin{array}{l}1975 \\
(\mathrm{nT})\end{array}$ & $\begin{array}{l}1980 \\
(\mathrm{nT})\end{array}$ & $\begin{array}{c}1980-85 \\
(\mathrm{nT} / \mathrm{yr})\end{array}$ \\
\hline g & 6 & 6 & -111 & -112 & -111 & -108 & -0.1 \\
\hline h & 6 & 6 & -7 & 1 & 11 & 17 & 0.0 \\
\hline $\mathrm{g}$ & 7 & 0 & 75 & 72 & 71 & 70 & -1.0 \\
\hline g & 7 & 1 & -57 & -57 & -56 & -59 & -0.8 \\
\hline $\mathrm{h}$ & 7 & 1 & -61 & -70 & -77 & -83 & -0.4 \\
\hline g & 7 & 2 & 4 & 1 & 1 & 2 & 0.4 \\
\hline $\mathrm{h}$ & 7 & 2 & -27 & -27 & -26 & -28 & 0.4 \\
\hline g & 7 & 3 & 13 & 14 & 16 & 20 & 0.5 \\
\hline $\mathrm{h}$ & 7 & 3 & -2 & -4 & -5 & -5 & 0.2 \\
\hline g & 7 & 4 & -26 & -22 & -14 & -13 & 1.6 \\
\hline $\mathrm{h}$ & 7 & 4 & 6 & 8 & 10 & 16 & 1.4 \\
\hline g & 7 & 5 & -6 & -2 & 0 & 1 & 0.1 \\
\hline $\mathrm{h}$ & 7 & 5 & 26 & 23 & 22 & 18 & -0.5 \\
\hline g & 7 & 6 & 13 & 13 & 12 & 11 & 0.1 \\
\hline h & 7 & 6 & -23 & -23 & -23 & -23 & -0.1 \\
\hline g & 7 & 7 & 1 & -2 & -5 & -2 & 0.0 \\
\hline $\mathrm{h}$ & 7 & 7 & -12 & -11 & -12 & -10 & 1.1 \\
\hline $\mathrm{g}$ & 8 & 0 & 13 & 14 & 14 & 20 & 0.8 \\
\hline g & 8 & 1 & 5 & 6 & 6 & 7 & -0.2 \\
\hline $\mathrm{h}$ & 8 & 1 & 7 & 7 & 6 & 7 & -0.1 \\
\hline $\mathrm{g}$ & 8 & 2 & -4 & -2 & -1 & 1 & -0.3 \\
\hline h & 8 & 2 & -12 & -15 & -16 & -18 & -0.7 \\
\hline $\mathrm{g}$ & 8 & 3 & -14 & -13 & -12 & -11 & 0.3 \\
\hline h & 8 & 3 & 9 & 6 & 4 & 4 & 0.0 \\
\hline $\mathrm{g}$ & 8 & 4 & 0 & -3 & -8 & -7 & -0.8 \\
\hline $\mathrm{h}$ & 8 & 4 & -16 & -17 & -19 & -22 & -0.8 \\
\hline g & 8 & 5 & 8 & 5 & 4 & 4 & -0.2 \\
\hline h & 8 & 5 & 4 & 6 & 6 & 9 & 0.2 \\
\hline $\mathrm{g}$ & 8 & 6 & -1 & 0 & 0 & 3 & 0.7 \\
\hline $\mathrm{h}$ & 8 & 6 & 24 & 21 & 18 & 16 & 0.2 \\
\hline $\mathrm{g}$ & 8 & 7 & 11 & 11 & 10 & 7 & -0.3 \\
\hline h & 8 & 7 & -3 & -6 & -10 & -13 & -1.1 \\
\hline g & 8 & 8 & 4 & 3 & 1 & -1 & 1.2 \\
\hline h & 8 & 8 & -17 & -16 & -17 & -15 & 0.8 \\
\hline $\mathrm{g}$ & 9 & 0 & 8 & 8 & 7 & 6 & \\
\hline $\mathrm{g}$ & 9 & 1 & 10 & 10 & 10 & 11 & \\
\hline $\mathrm{h}$ & 9 & 1 & -22 & -21 & -21 & -21 & \\
\hline $\mathrm{g}$ & 9 & 2 & 2 & 2 & 2 & 2 & \\
\hline $\mathrm{h}$ & 9 & 2 & 15 & 16 & 16 & 16 & \\
\hline g & 9 & 3 & -13 & -12 & -12 & -12 & \\
\hline $\mathrm{h}$ & 9 & 3 & 7 & 6 & 7 & 9 & \\
\hline g & 9 & 4 & 10 & 10 & 10 & 9 & \\
\hline $\mathrm{h}$ & 9 & 4 & -4 & -4 & -4 & -5 & \\
\hline $\mathrm{g}$ & 9 & 5 & -1 & -1 & -1 & -3 & \\
\hline $\mathrm{h}$ & 9 & 5 & -5 & -5 & -5 & -7 & \\
\hline
\end{tabular}


Table 2. (continued)

\begin{tabular}{|c|c|c|c|c|c|c|c|}
\hline & \multirow{2}{*}{$n$} & \multirow[b]{2}{*}{$m$} & \multicolumn{3}{|c|}{ DGRF } & \multicolumn{2}{|c|}{ IGRF } \\
\hline & & & $\begin{array}{l}1965 \\
(\mathrm{nT})\end{array}$ & $\begin{array}{l}1970 \\
(n T)\end{array}$ & $\begin{array}{l}1975 \\
(\mathrm{nT})\end{array}$ & $\begin{array}{l}1980 \\
(n T)\end{array}$ & $\begin{array}{c}1980-85 \\
(\mathrm{nT} / \mathrm{yr})\end{array}$ \\
\hline g & 9 & 6 & -1 & 0 & -1 & -1 & \\
\hline h & 9 & 6 & 10 & 10 & 10 & 9 & \\
\hline g & 9 & 7 & 5 & 3 & 4 & 7 & \\
\hline $\mathrm{h}$ & 9 & 7 & 10 & 11 & 11 & 10 & \\
\hline g & 9 & 8 & 1 & 1 & 1 & 1 & \\
\hline $\mathrm{h}$ & 9 & 8 & -4 & -2 & -3 & -6 & \\
\hline g & 9 & 9 & -2 & -1 & -2 & -5 & \\
\hline $\mathrm{h}$ & 9 & 9 & 1 & 1 & 1 & 2 & \\
\hline $\mathrm{g}$ & 10 & 0 & -2 & -3 & -3 & -3 & \\
\hline g & 10 & 1 & -3 & -3 & -3 & -4 & \\
\hline $\mathrm{h}$ & 10 & 1 & 2 & 1 & 1 & 1 & \\
\hline g & 10 & 2 & 2 & 2 & 2 & 2 & \\
\hline $\mathrm{h}$ & 10 & 2 & 1 & 1 & 1 & 1 & \\
\hline g & 10 & 3 & -5 & -5 & -5 & -5 & \\
\hline h & 10 & 3 & 2 & 3 & 3 & 2 & \\
\hline g & 10 & 4 & -2 & -1 & -2 & -2 & \\
\hline $\mathrm{h}$ & 10 & 4 & 6 & 4 & 4 & 5 & \\
\hline g & 10 & 5 & 4 & 6 & 5 & 5 & \\
\hline $\mathrm{h}$ & 10 & 5 & -4 & -4 & -4 & -4 & \\
\hline g & 10 & 6 & 4 & 4 & 4 & 3 & \\
\hline $\mathrm{h}$ & 10 & 6 & 0 & 0 & -1 & -1 & \\
\hline g & 10 & 7 & 0 & 1 & 1 & 1 & \\
\hline $\mathrm{h}$ & 10 & 7 & -2 & -1 & -1 & -2 & \\
\hline g & 10 & 8 & 2 & 0 & 0 & 2 & \\
\hline h & 10 & 8 & 3 & 3 & 3 & 4 & \\
\hline $\mathbf{g}$ & 10 & 9 & 2 & 3 & 3 & 3 & \\
\hline $\mathrm{h}$ & 10 & 9 & 0 & 1 & 1 & -1 & \\
\hline $\mathrm{g}$ & 10 & 10 & 0 & -1 & -1 & 0 & \\
\hline h & 10 & 10 & -6 & -4 & -5 & -6 & \\
\hline
\end{tabular}

where

$$
f=\left\{h\left[A^{2}-\left(A^{2}-B^{2}\right) \sin ^{2} \phi\right]^{1 / 2}+A^{2}\right\}^{2} /\left\{h\left[A^{2}-\left(A^{2}-B^{2}\right) \sin ^{2} \phi\right]^{1 / 2}+B^{2}\right\}^{2},
$$

$\phi$ is the geographic latitude, and $h$ is the elevation above mean sea level. The field components $X$ (northward), $Y$ (eastward), and $Z$ (vertically downward) in a local cartesian coordinate system referred to an oblate-spheroidal Earth are obtained from:

$$
\begin{aligned}
& X=X_{\mathrm{c}} \cos \delta+Z_{\mathrm{c}} \sin \delta \\
& Y=Y_{\mathrm{c}} \\
& Z=-X_{\mathrm{c}} \sin \delta+Z_{\mathrm{c}} \cos \delta
\end{aligned}
$$


where

$$
\delta=\phi+\theta-90
$$

As for the earlier generations of the IGRF, the oblate spheroid having equatorial radius $A$ $=6,378.160 \mathrm{~km}$ and polar radius $B=6,356.775 \mathrm{~km}$ (INTERNATIONAL ASTRONOMICAL UNION, 1966) is recommended. The other geomagnetic elements $H$ (horizontal intensity), $F$ (total intensity), $D$ (declination), and $I$ (inclination) can be obtained from:

$$
\begin{aligned}
H & =\left(X^{2}+Y^{2}\right)^{1 / 2} \\
F & =\left(H^{2}+Z^{2}\right)^{1 / 2} \\
D & =\tan ^{-1}(Y / X) \\
I & =\tan ^{-1}(Z / H)
\end{aligned}
$$

\section{The Present State of the IGRF}

Figure 1 may be of some help in trying to visualize the present state of the IGRF, and to understand the relations between its constituent models. Pictured, as a function of time, is a hypothetical value $C$ associated with the IGRF. $C$ can represent one of the field components $X, Y$, or $Z$ calculated from the IGRF or, alternatively, it can represent a spherical harmonic coefficient of a particular degree and order. A small circle indicates that $C$ is derived directly
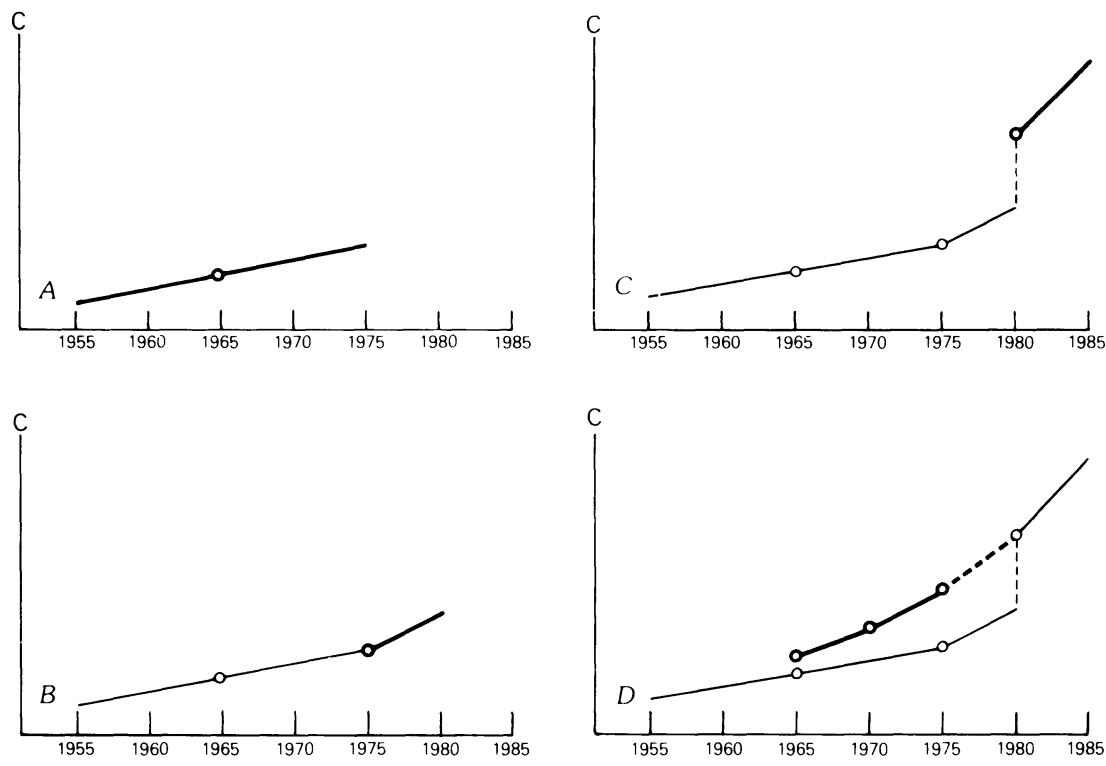

Fig. 1. A hypothetical value $C$ associated with the IGRF. $C$ can represent one of the field components $X, Y$, or $Z$ calculated from the IGRF, or alternatively it can represent an IGRF spherical harmonic coefficient of a particular degree and order. See text for more information. The lines and small circles of each frame are reproduced, in lighter form, in all succeeding frames. IGRF 1965 is represented in (A). IGRF 1975 is represented in (B). IGRF 1980 is represented in (C). The DGRF series and the PGRF (heavy dashed line) are represented in (D). 
from a main-field model. A line indicates that it is derived either by extrapolating a mainfield model using a secular variation model or by interpolating between two main-field models. Note that the lines and small circles of each frame of the figure are reproduced, in lighter form, in all succeeding frames.

IGRF 1965 is represented in Fig. 1(A). The constant rate of change specified by the secular variation model produces a straight line from 1955.0 to 1975.0. IGRF 1975 is represented in Fig. 1(B). The main-field model of IGRF 1975 is simply the main-field model of IGRF 1965 extrapolated to 1975.0. The secular variation model was new, and produces an abrupt change in the slope of the line at 1975.0. IGRF 1980 is represented in Fig. 1(C). The new model of the main field at 1980.0 is not continuous with IGRF 1975 at 1980.0 (dashed line). The IGRF 1980 secular variation model is new and causes yet another change of slope. The DGRF series of models and the PGRF (heavy dashed line) are represented in Fig. 1(D). Linear interpolation is specified for intervening dates, therefore the connecting lines are straight. The DGRF series is a more accurate description of the real field than is the IGRF series, which is pictured diverging until 1980.0.

\section{Conclusion}

The complete International Geomagnetic Reference Field now consists of two series of models, the IGRF series and the DGRF series, and an interpolative bridge, the PGRF. The present plan calls for the periodic extension of these two series.

The IGRF series is made up of models of the main field at specified epochs and associated models of the secular variation of the main field. The secular variation models are predictive in nature. The IGRF series has only one discontinuity thus far, at 1980.0. Because of our inability to accurately predict the secular variation, additional discontinuities may be required in the future as the series is advanced.

The DGRF series is made up of models of the main field at specified epochs. The models are definitive in nature, having been derived using sets of data that are unlikely ever to be significantly increased or improved. The description of the main field at dates intermediate to the specified epochs is specified by linear interpolation of the model coefficients. Thus, the description of the main field given by the DGRF series is continuous in time.

PGRF 1975 is a temporary bridge between the two series of models. Other PGRF's may be required in the future.

Users of the IGRF should remember not to interpolate (in time) on the elements $D, I$, $H$, or $F$ because they are not linear functions of the spherical harmonic coefficients. The correct methods are either to interpolate on the coefficients first, and then compute the desired element(s), or to compute $X, Y$, and $Z$ first, interpolate on these, and then compute the desired element(s).

World contour maps of the values at sea level of the geomagnetic elements $D, I, H, X$, $Y, Z, F$, and their annual change, based on IGRF 1980, are shown in Figs. 2-15 (taken from Fabiano et al., 1982, which includes tables of grid values).

The IGRF coefficients in computer-readable form, as well as programs for synthesizing field values, are available from:

(1) World Data Center A for Rockets and Satellites Code 601 


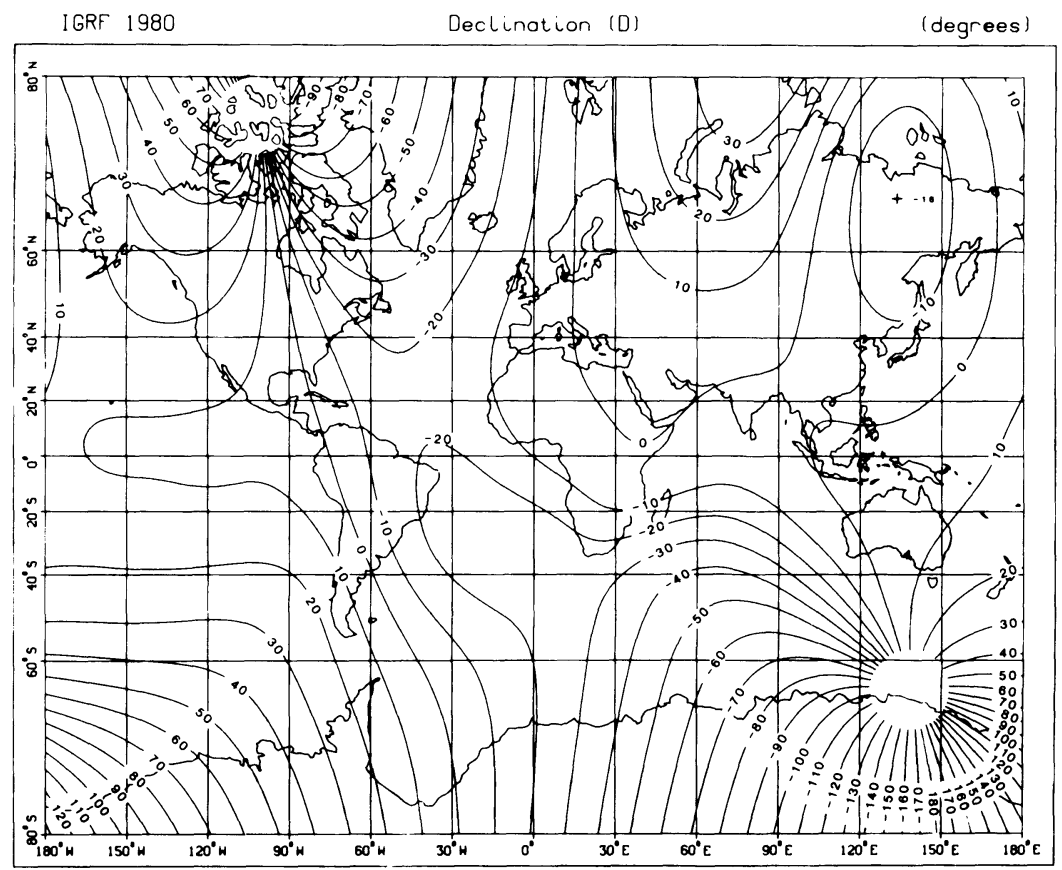

Fig. 2. Declination $(D)$.

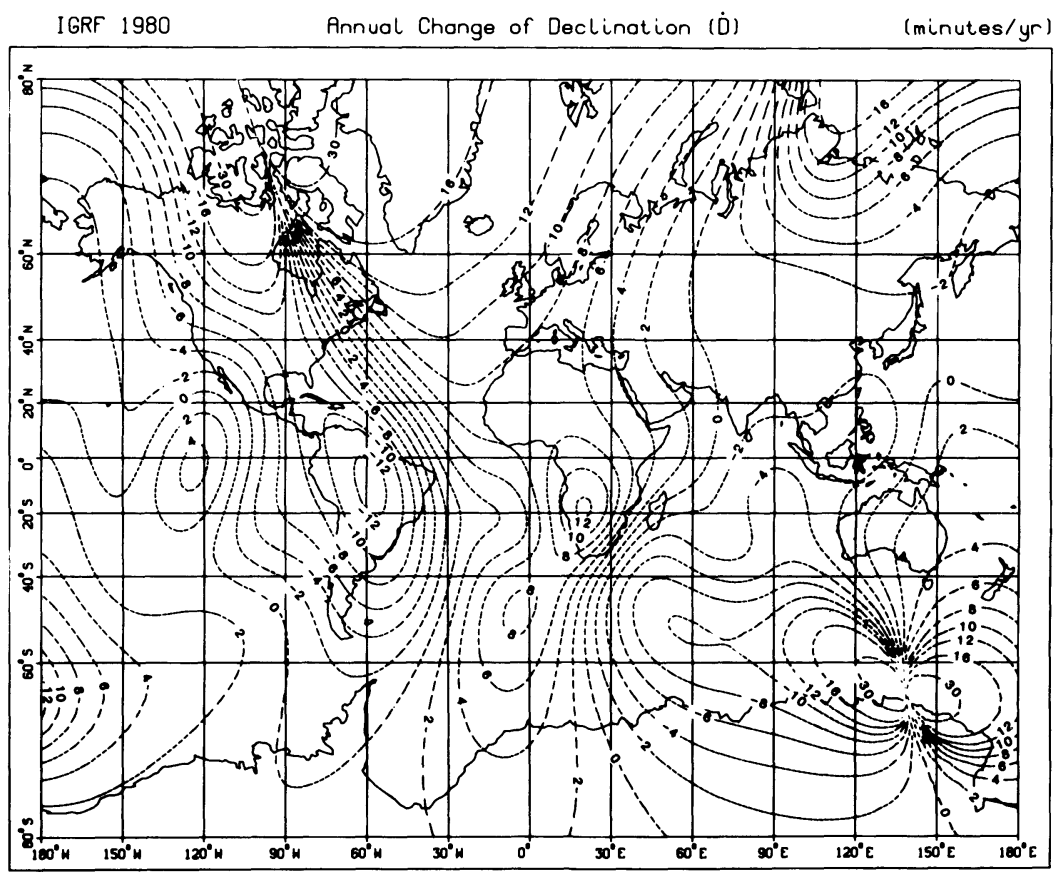

Fig. 3. Annual change of declination $(\dot{D})$. 


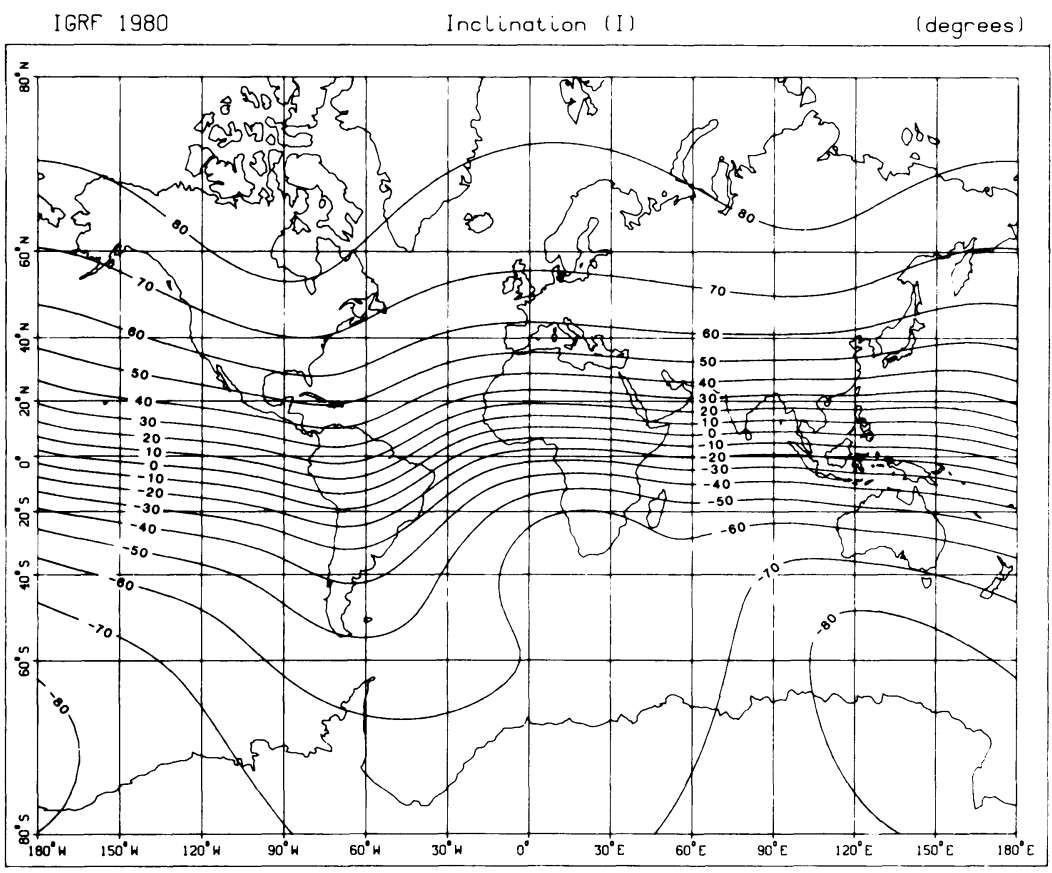

Fig. 4. Inclination $(I)$.

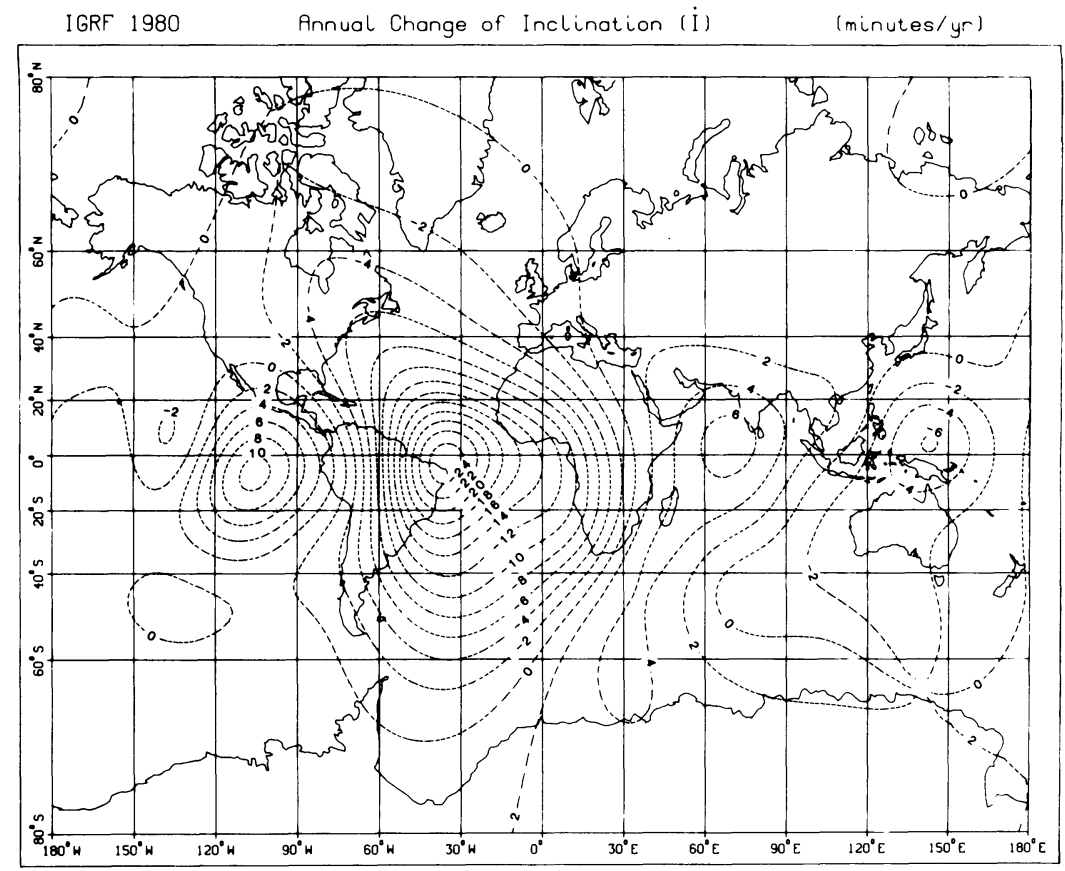

Fig. 5. Annual change of inclination $(\dot{I})$. 


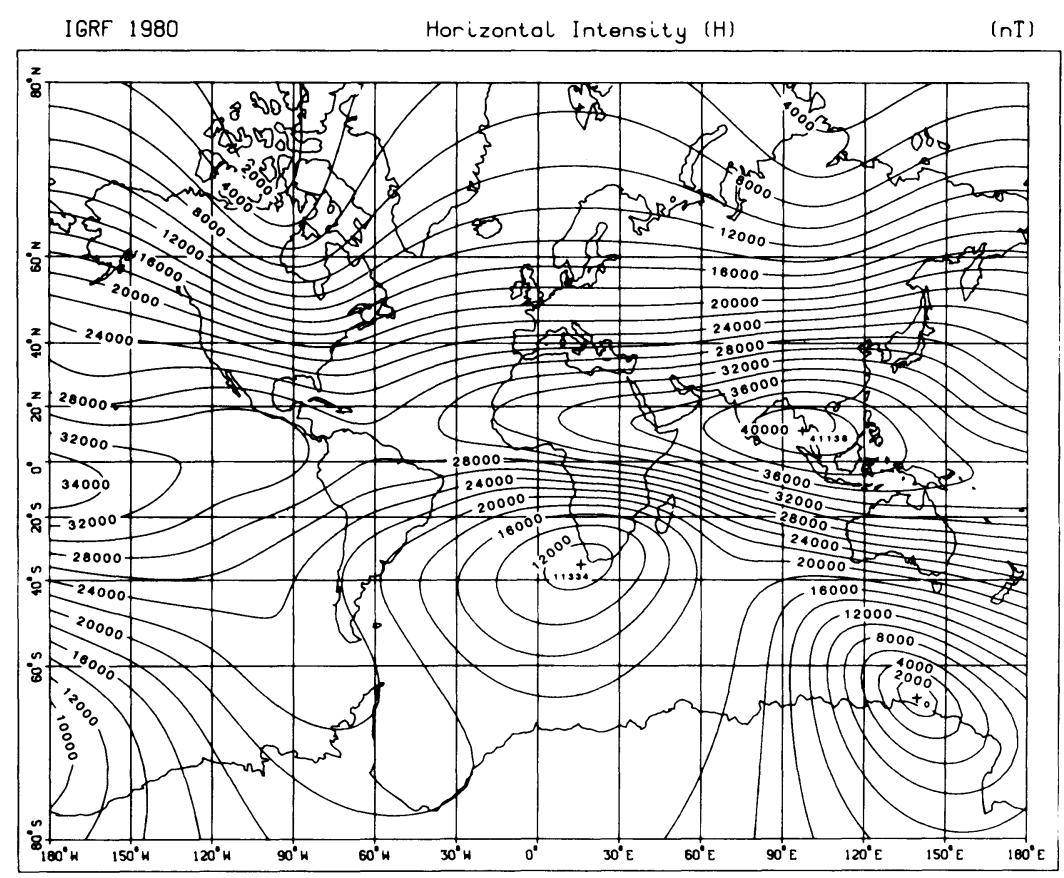

Fig. 6. Horizontal intensity $(H)$.

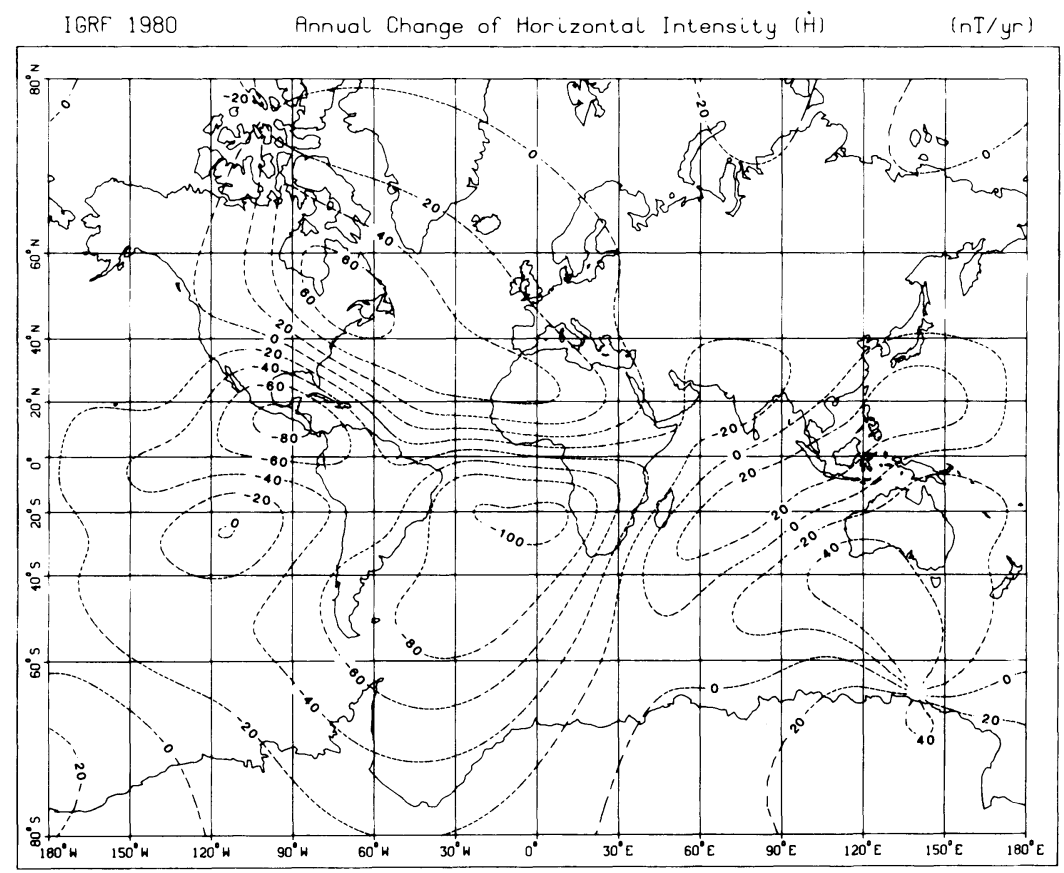

Fig. 7. Annual change of horizontal intensity $(\dot{H})$. 


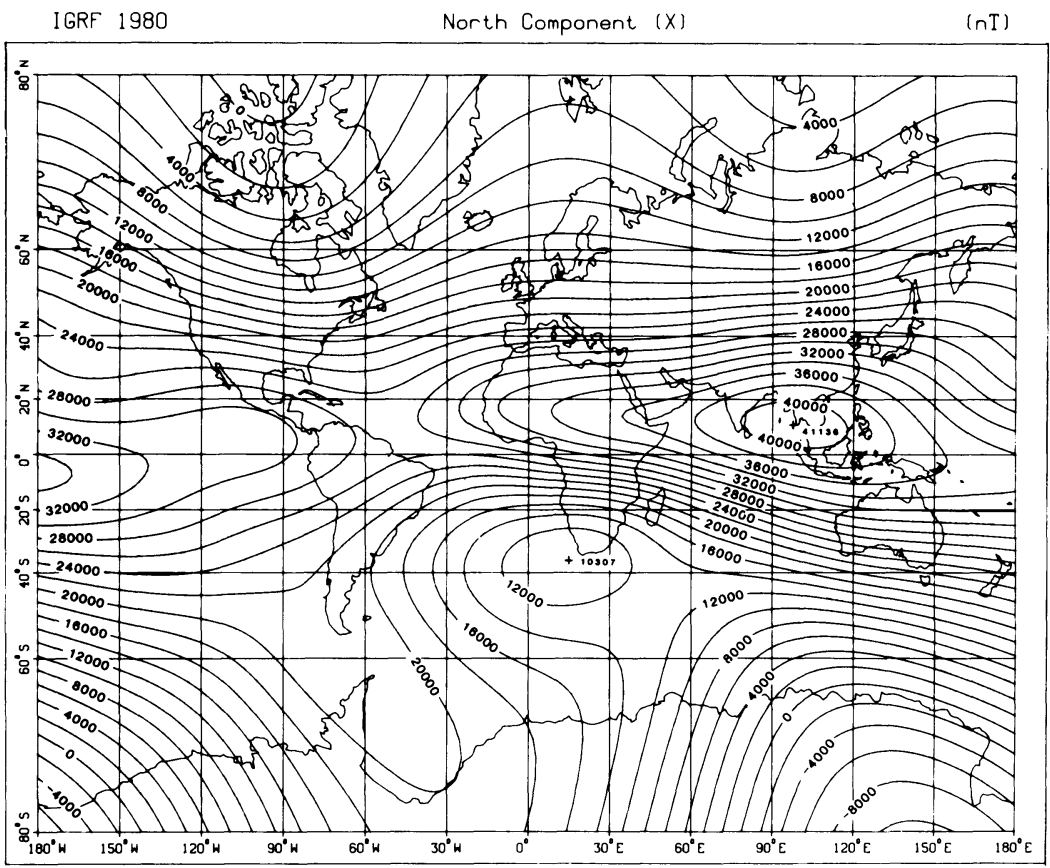

Fig. 8. North component $(X)$.

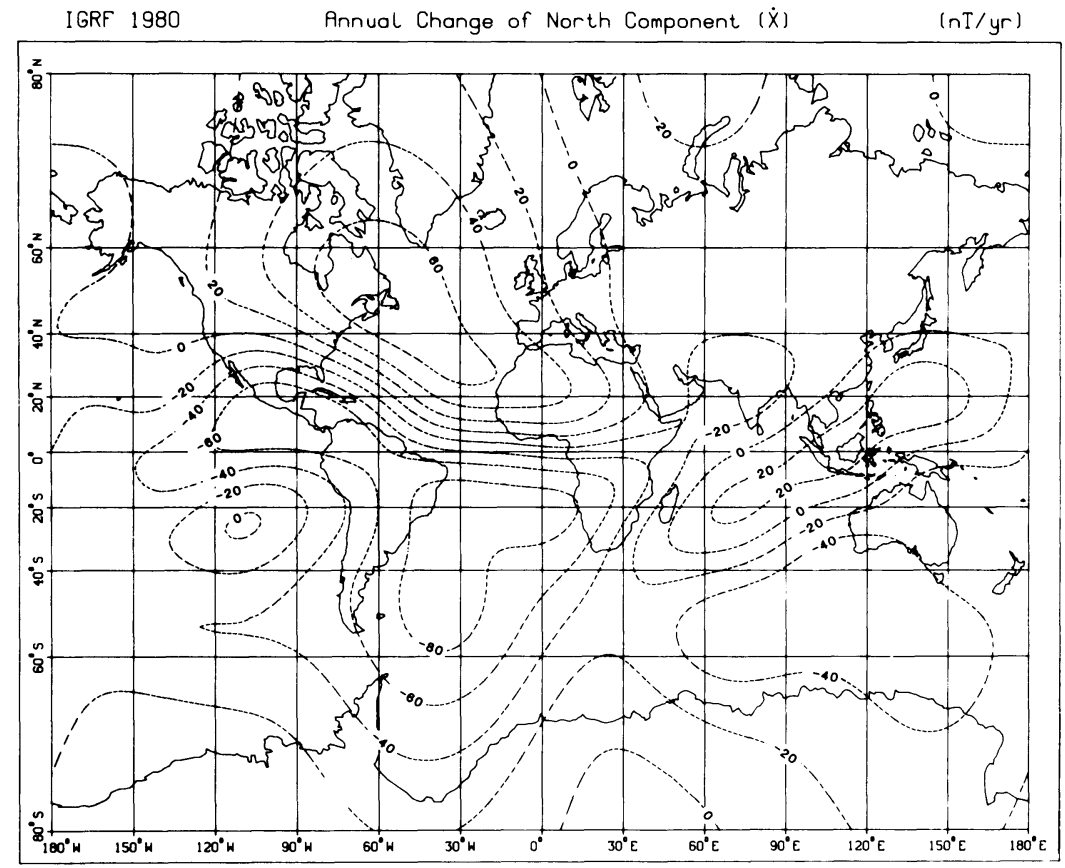

Fig. 9. Annual change of north component $(\dot{X})$. 


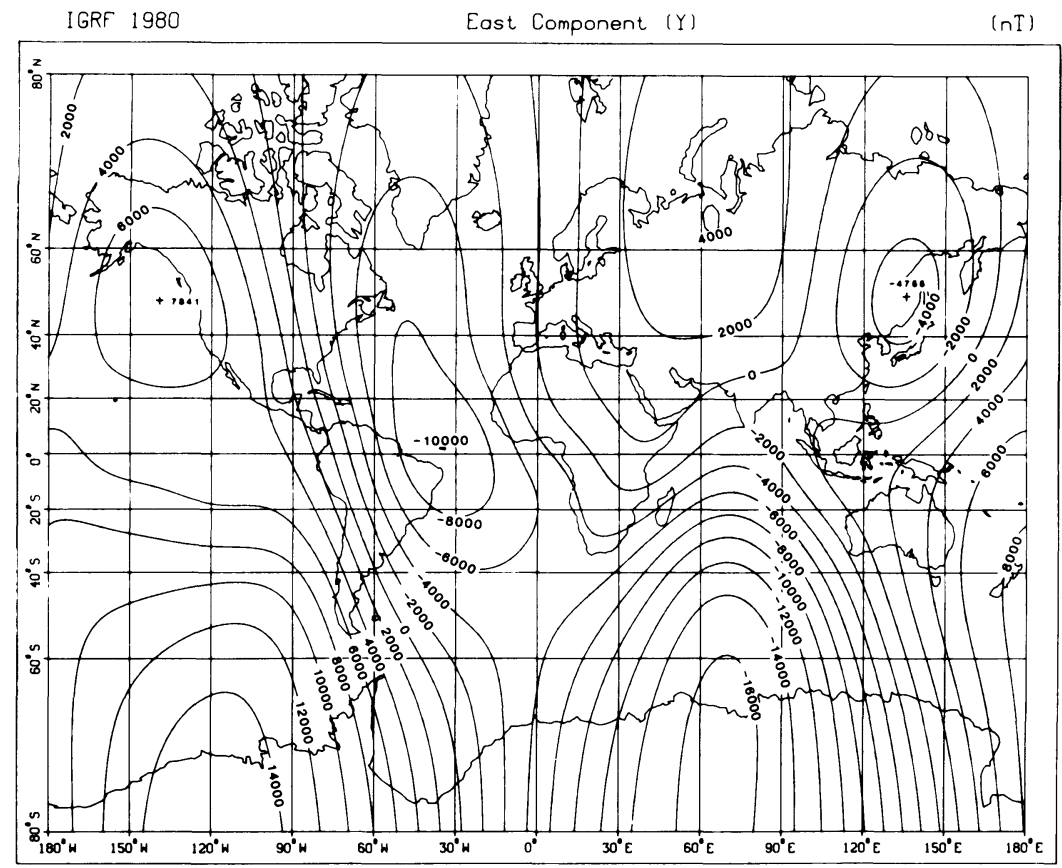

Fig. 10. East component $(Y)$.

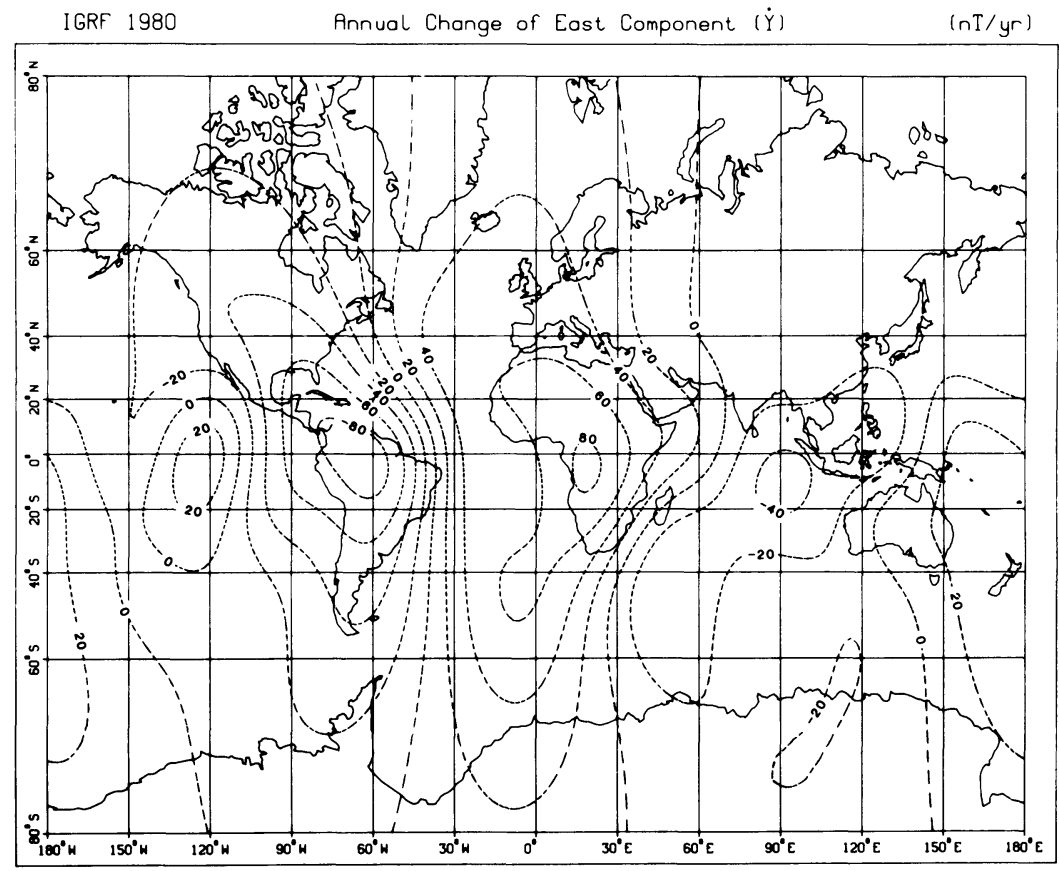

Fig. 11. Annual change of east component $(\dot{Y})$. 


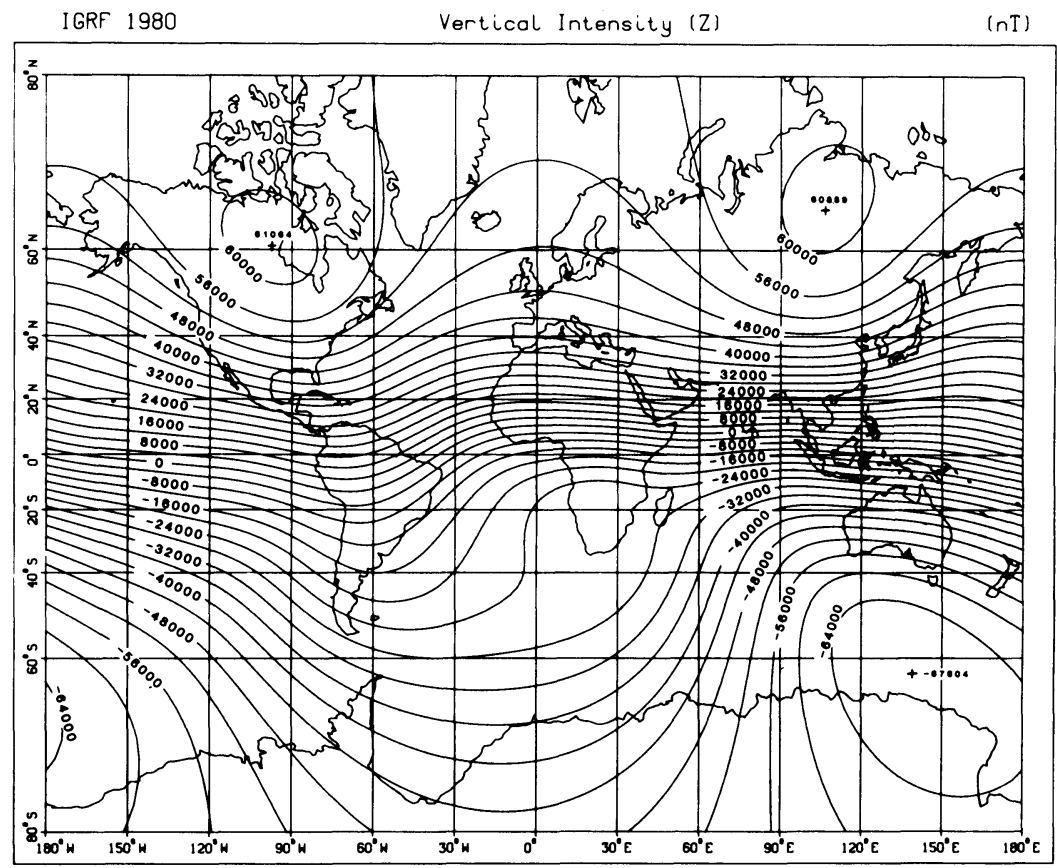

Fig. 12. Vertical intensity $(Z)$.

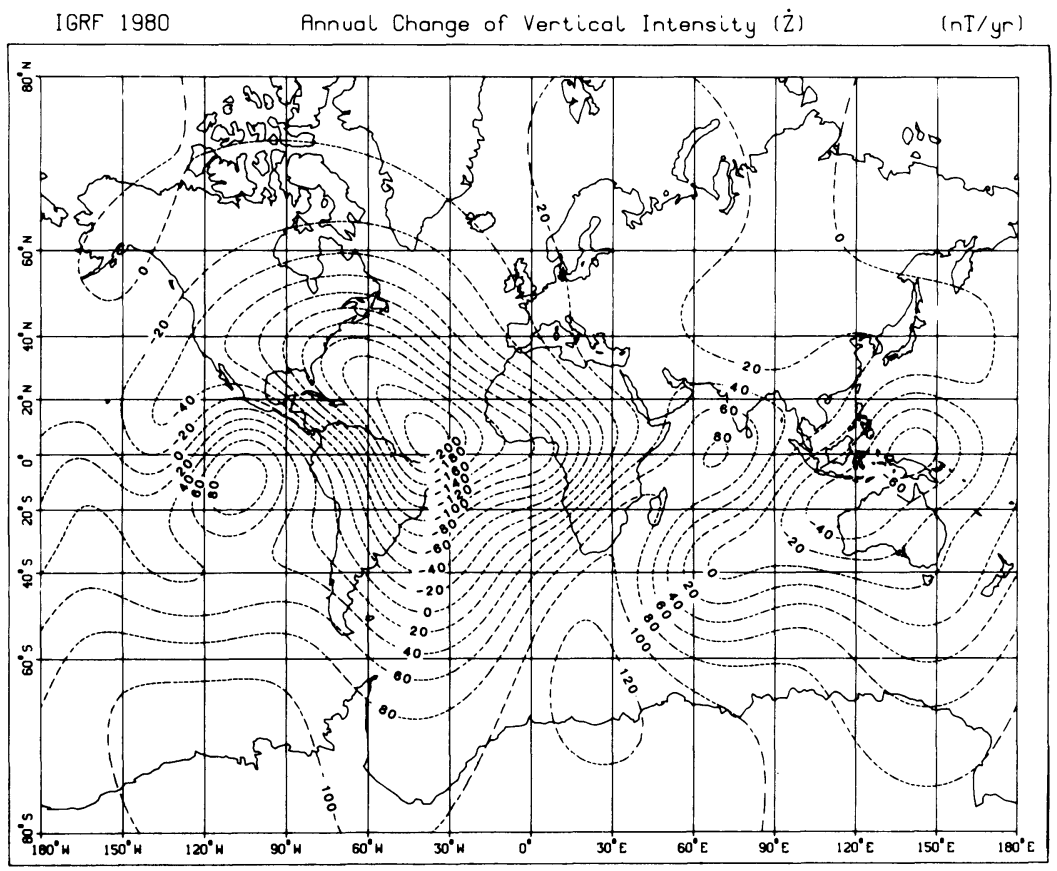

Fig. 13. Annual change of vertical intensity $(\dot{Z})$. 


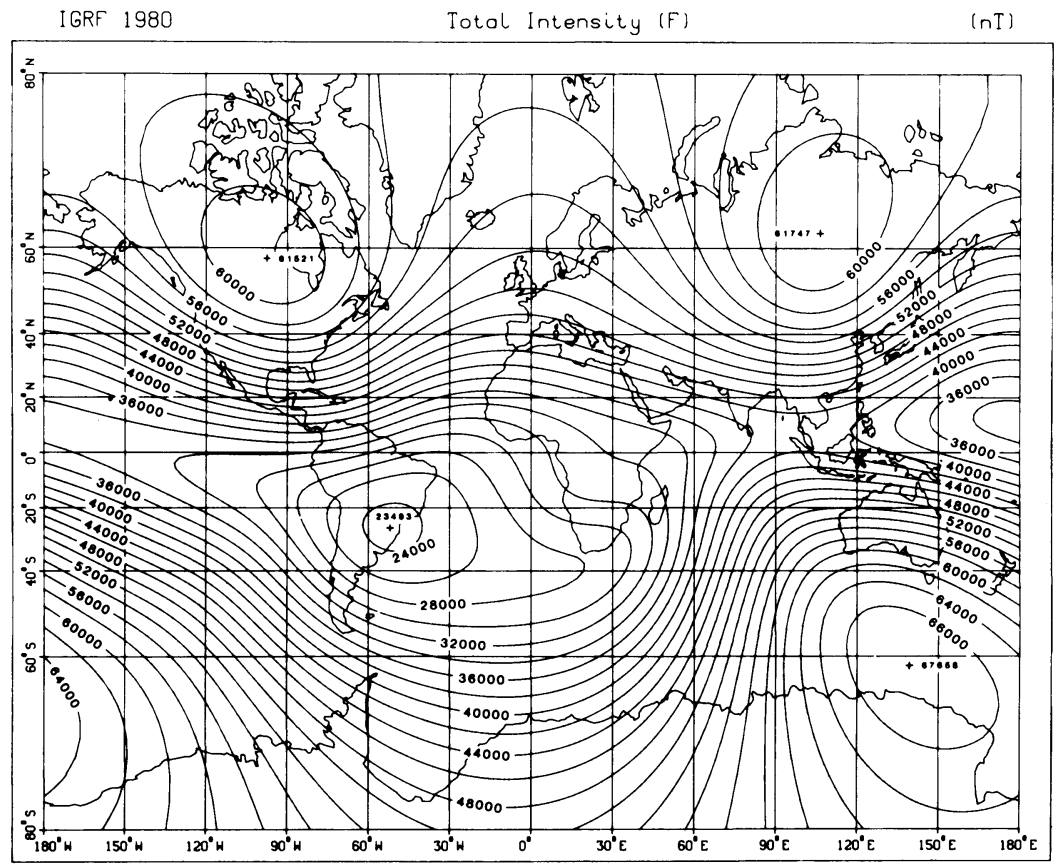

Fig. 14. Total intensity $(F)$.

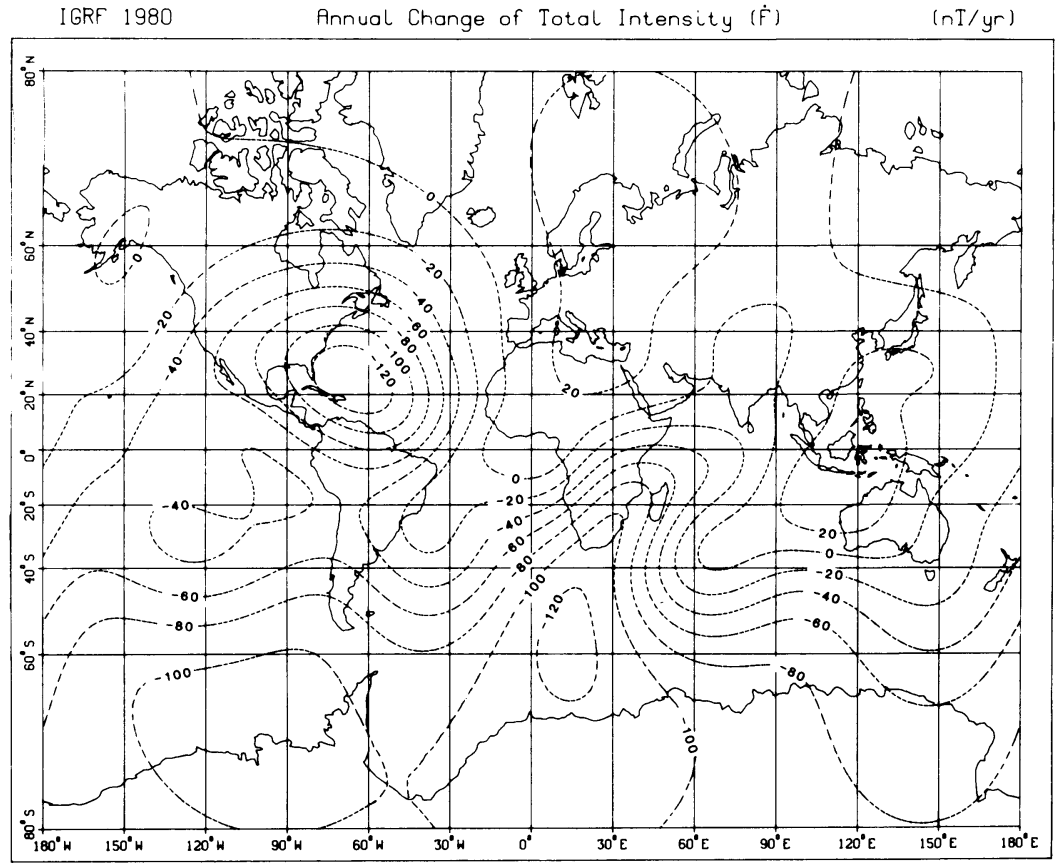

Fig. 15. Annual change of total intensity $(\dot{F})$. 
NASA/Goddard Space Flight Center

Greenbelt, MD 20771 USA

(2) World Digital Data Centre $\mathrm{Cl}$

Geomagnetism Unit

Institute of Geological Sciences

Murchison House, West Mains Road

Edinburgh, EH9 3LA UK

(3) World Data Center A

National Oceanic and Atmospheric Administration

EDIS/NGSDC (D62)

325 Broadway

Boulder, CO 80303 USA

\section{REFERENCES}

BARRAClough, D. R., Evaluation of IGRF 1980 candidate models, J. Geomag. Geoelectr., this issue, 383-385, 1982.

Barraclough, D. R., B. M. Hodder, and S. R. C. Malin, The IGS proposal for the new International Geomagnetic Reference Field, J. Geomag. Geoelectr., this issue, 351-356, 1982.

Chapman, S. and J. Bartels, Geomagnetism, Vol. 2, pp. 611-612, Oxford Univ. Press, New York, 1940.

Dawson, E. and L. R. Newitt, IGRF comparisons, Phys. Earth Planet. Inter., 16, P1-P6, 1978.

DA wson, E. and L. R. NEwITT, Comparison of IGRF models with North American magnetic data, J. Geomag. Geoelectr., this issue, 393-400, 1982.

Fabiano, E. B., N. W. Peddie, D. R. Barraclough, and A. Zunde, International Geomagnetic Reference Field 1980 : charts and grid values, U.S. Geol. Survey Open File Report 82-377 (IAGA Bull. No. 47), 1982.

Fukushima, N. (ed.), IAGA Trans. XVII Gen. Assem., Canberra, Australia, 1979 (IAGA Bulletin No. 44), 40, 1980.

IAGA Commission 2 Working Group 4, International Geomagnetic Reference Field 1965.0, J. Geophys. Res., 74, 4407-4408; J. Geomag. Geoelectr., 21, 569; Geomag. Aeron., 9, 956; 1969.

IAGA Division I Study Group on Geomagnetic Reference Fields, International Geomagnetic Reference Field 1975, J. Geomag. Geoelectr., 27, 437-439, 1975; Geophys. J. R. Astr. Soc., 44, 733-734, 1976; J. Geophys. Res., 81, 5163-5164, 1976; Geomag. Aeron., 17, 167-168, 1977.

IAGA Division I Working Group 1, International Geomagnetic Reference Fields: DGRF 1965, DGRF 1970, DGRF 1975, and IGRF 1980, EOS Trans. AGU, 62, 1169, 1981. See also BARRAClOUGH, D. R., The 1980 Geomagnetic Reference Field, Nature, 294, 14-15, 1981; PedDIE, N. W., International Geomagnetic Reference Field 1980 : a report by IAGA Division I Working Group 1, Geophys. J. R. Astr. Soc., 68, 265-268, 1982 ; Peddie, N. W., International Geomagnetic Reference Field 1980, Eur. Geophys. Soc. Newslett., No. 20 (Dec 1981), 44-49, 1981.

International Astronomical Union, Proceedings of the Twelfth General Assembly, Hamburg, Germany, 12B, pp. 594-595, 1966.

Langel, R. A. and R. H. Estes, Comparison of candidate IGRF models, J. Geomag. Geoelectr., this issue, $365-381,1982$.

LANGel, R. A., R. H. Estes, and G. D. Mead, Some new methods in geomagnetic field modeling applied to the 1960-1980 epoch, J. Geomag. Geoelectr., this issue, 327-349, 1982a.

Langel, R., G. Ousley, J. Berbert, J. Murphy, and M. Settle, The MAGSAT mission, Geophys, Res. Lett., 9, 243-245, $1982 \mathrm{~b}$.

MCGregor, P. M., D. E. WINCH, and A. J. McEwIN, A preliminary assessment of International Geomagnetic Reference Field models for Australia, J. Geomag. Geoelectr., this issue, 411-416, 1982.

Mead, G. D., An evaluation of recent internal field models, in Quantitative Modeling of Magnetospheric Processes, edited by W. P. Olson, A.G.U. Geophysical Monograph 21, pp. 110-117, 1979.

Ostrowski, J. A., A comparison of the proposed IGRF models: internal and relative consistencies, J. Geomag. Geoelectr., this issue, 417-422, 1982. 
Peddie, N. W. and E. B. Fabiano, A proposed International Geomagnetic Reference Field for 1965-1985, J. Geomag. Geoelectr., this issue, 357-364, 1982a.

Peddie, N. W. and E. B. Fabiano, Assessment of the models proposed for the 1981 revision of the IGRF, $J$. Geomag. Geoelectr., this issue, 387-392, $1982 \mathrm{~b}$.

Petkovik, J. J. and R. Whit woRTh, Problems in secular variation in the Australian region (abstract), EOS Trans. $A G U, 56,547,1975$.

Zmuda, A. J. (ed.), World Magnetic Survey 1957-1969 (IAGA Bulletin No. 28), Paris, 1971. 